\title{
Mechanism and Effect of Activating Agent on Mechanical Performance of Steel Slag Composite Materials
}

\author{
Tian Xiushu*, Han Yufang and Hou Weifang
}

School of Material Science and Engineering, Shijiazhuang Tiedao University, Shijiazhuang, Hebei, 050043, P.R. China

\begin{abstract}
This study investigates the effect of three kinds of activating agent on the mechanical performance of steel slag composite materials. Hydration products of the pastes at different ages are investigated by XRD. The results show that compared with the calcium hydroxide, gypsum and sodium sulfate can excite the activation of steel slag more effectively. When amount of gypsum is $1.5 \%$, the $3 \mathrm{~d}$ strength increases to $1.2 \mathrm{MPa}, 7 \mathrm{~d}$ strength increases to $3.3 \mathrm{MPa}, 28 \mathrm{~d}$ strength increases to $5.0 \mathrm{MPa}$. $\mathrm{Ca}^{2+}$ and $\mathrm{SO}_{4}{ }^{2-}$ are provided by gypsum, $\mathrm{SiO}_{2}, \mathrm{Fe}_{2} \mathrm{O}_{3}$ and $\mathrm{Al}_{2} \mathrm{O}_{3}$ in steel slag act with $\mathrm{Ca}(\mathrm{OH})_{2}$, hydration products such as hydrated calcium silicate, are generated in the paste. Enhancement of early strength may be attributed to rapidly consumption of $\mathrm{Al}_{2} \mathrm{O}_{3}$ in steel slag and $\mathrm{Ca}(\mathrm{OH})_{2}$. When amount of $\mathrm{Na}_{2} \mathrm{SO}_{4}$ is $1.5 \%$, the $3 \mathrm{~d}$ strength increases to $5.1 \mathrm{MPa}, 7 \mathrm{~d}$ strength increases to $6.5 \mathrm{MPa}, 28 \mathrm{~d}$ strength increases to $15.5 \mathrm{MPa}$. XRD patterns show that the main products are consist of hydrated calcium silicate, Aft and calcium hydroxide. These products are bonded together, fill the void of paste, so the density increased, and higher strength are obtained.
\end{abstract}

Keywords: Activator, mechanical property, steel slag.

\section{INTRODUCTION}

Steel slag is a kind of by-product in the process of steel making [1]. It has become an important industrial wastes in China. Only $10 \%$ of steel slag is currently used again in China [2], storage of large amount of steel slag will occupy land resources, cause water pollution, environmental pollution and soil pollution. So more concern has been paid to reuse steel slag [3].

It shows that $\mathrm{C}_{2} \mathrm{~S}, \mathrm{C}_{3} \mathrm{~S}, \mathrm{C}_{4} \mathrm{AF}$ and other minerals exist in the steel slag, which provide the gelling properties of steel slag, but "dead burned" is formed during melting at high temperature, hydration activity of $\mathrm{C}_{3} \mathrm{~S}$ must be activated in a very long time, $\mathrm{C}_{2} \mathrm{~S}$ only contributes to the later strength, so hydration performance of steel slag is very poor. The improvement of steel slag's cementitious activity has become one of the important ways to promote the widely used of steel slag in architecture [4 6]. At present, active activation of steel slag are studied by domestic and foreign researchers, and some achievements have been made [7 11]. The chemical compositions of steel slag vary greatly with preparation materials and production technology, the effect of different activator on the hydration process and mechanical performance of steel slag is different. In this paper, the effect of calcium hydroxide and gypsum, sodium sulfate on mechanical performance of steel slag are studied, hydration products is analyzed by XRD.

\section{MATERIALS AND EXPERIMENTS}

\subsection{Materials}

The steel slag adopted in this experiment is produced by a steel plant in Qianan, with grain size of less than $5 \mathrm{~mm}$. It was dried, crushed and ground in a ball mill, until the specific surface area less than $450 \mathrm{~m}^{2} / \mathrm{kg}$. Calcium hydroxide, gypsum and sodium sulfate are used as activators.

\subsection{Specimen Molding}

Adjust the consistency of the plastic paste to $28 \pm 2 \mathrm{~mm}$. Samples of $20 \times 20 \times 20 \mathrm{~mm}$ were prepared. After molding, the samples were cured at $20 \pm 1^{\circ} \mathrm{C}(95 \%$ R.H. $)$ for $1 \mathrm{~d}$, then samples were demolded, put in natural water for different ages.

\subsection{Testing}

The compression strength of specimen was measured by compression-testing machine (NYL-60). Phase analysis of material was identified by X-ray diffraction $(\mathrm{Cu} k \alpha$ radiation, $\lambda=0.15418 \mu \mathrm{m}$ ).

\section{RESULTS AND DISCUSSIONS}

\subsection{Effect of Calcium Hydroxide on Mechanical Performance of Steel Slag}

The effect of calcium hydroxide on compression strength of $3 \mathrm{~d}, 7 \mathrm{~d}$ and $28 \mathrm{~d}$ is shown in Fig. (1). As shown in the figure, the compression strength of the samples is increased, 
when the content of $\mathrm{Ca}(\mathrm{OH})_{2}$ is increased, and decreased when the amount of $\mathrm{Ca}(\mathrm{OH})_{2}$ exceeds $1.5 \%$. As the amount of $\mathrm{Ca}(\mathrm{OH})_{2}$ is $1.5 \%$, strength of $3 \mathrm{~d}$ increased about $100 \%$, $28 \mathrm{~d}$ strength increased about $69.2 \%$. As the content of $\mathrm{Ca}(\mathrm{OH})_{2}$ is $1.0 \%$, the the strength of $7 \mathrm{~d}$ increased about $300 \%$.

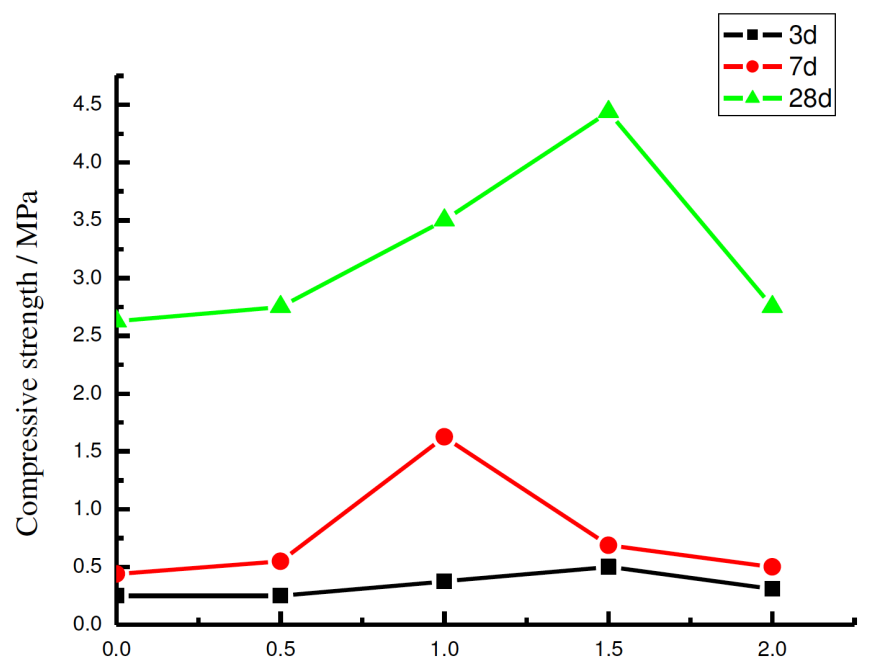

Fig. (1). Effect of $\mathrm{Ca}(\mathrm{OH})_{2}$ on compressive strength.

When $\mathrm{Ca}(\mathrm{OH})_{2}$ is used as activator, vitreous silica structure dissociated rapidly under the excitation function of $\mathrm{Ca} 2+, \mathrm{OH}-$ and other ions, ionic group of $\mathrm{Si}-\mathrm{O}$ and $\mathrm{Al}-\mathrm{O}$ dissolve out and act with ions released by steel slag to form C-S-H-Al gel. During hydration of steel slag, the products fill or connection in the network structure, the structure of steel slag becomes compacting gradually, the macro performance is the enhancement of strength. When amount of $\mathrm{Ca}(\mathrm{OH})_{2}$ is higher, $\mathrm{Ca}^{2+}$ increased, system has a relatively high ratio of $\mathrm{Ca}$ to $\mathrm{Si}$, double electronic layer is formed on the surface of particles, hydration of steel slag is limited, which result in poor strength.

\subsection{Effect of Gypsum on Mechanical Performance of Steel Slag}

Influence of gypsum on compression strength of $3 \mathrm{~d}, 7 \mathrm{~d}$ and $28 \mathrm{~d}$ is shown in Fig. (2). As shown in this figure, the compression strength of samples increased with the content of gypsum. As content of gypsum is $1.5 \%$, compression strength of $3 \mathrm{~d}$ increased to $1.2 \mathrm{MPa}$, the strength of $7 \mathrm{~d}$ increased to $3.3 \mathrm{MPa}$, the strength of $28 \mathrm{~d}$ increased to 5.0MPa.

It reveals that, gypsum can enhance hydration of steel slag in paste. $\mathrm{Ca}^{2+}$ and $\mathrm{SO}_{4}{ }^{2-}$ are provided by gypsum, $\mathrm{SiO}_{2}$, $\mathrm{Fe}_{2} \mathrm{O}_{3}$ and $\mathrm{Al}_{2} \mathrm{O}_{3}$ in steel slag act with $\mathrm{Ca}(\mathrm{OH})_{2}$, hydration products such as calcium silicate hydrates, are generated in the paste. Enhancement of early strength may be attributed to rapidly consumption of $\mathrm{Al}_{2} \mathrm{O}_{3}$ in steel slag and $\mathrm{Ca}(\mathrm{OH})_{2}$. With time going on, nuclear of liquid phase increase, small size crystals generate and contact each other. With the increase of hydration products, the crystal structures continue to be filled, the strength of paste can be improved.

\subsection{Influence of Sodium Sulfate on Mechanical Performance of Steel Slag}

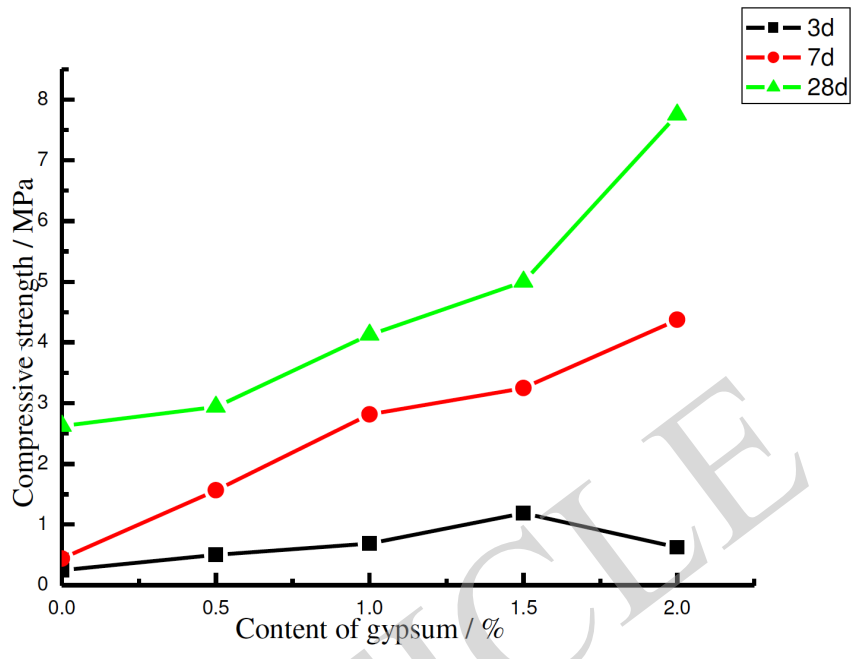

Fig. (2). Influence of gypsum on compression strength.

The influence of sodium sulfate on compression strength of $3 d, 7 d$ and $28 d$ is shown in Fig. (3). It can be seen that, the compression strength of samples are improved with the increasing content of sodium sulfate, decreases slowly as the amount is higher than $1.5 \%$. As the content of sodium sulfate is $1.5 \%$, the strength of $3 \mathrm{~d}$ has increased from $0.3 \mathrm{MPa}$ to $5.1 \mathrm{MPa}$, the strength of $7 \mathrm{~d}$ has increased to $6.5 \mathrm{MPa}$, the strength of $28 \mathrm{~d}$ has increased to $15.5 \mathrm{MPa}$.

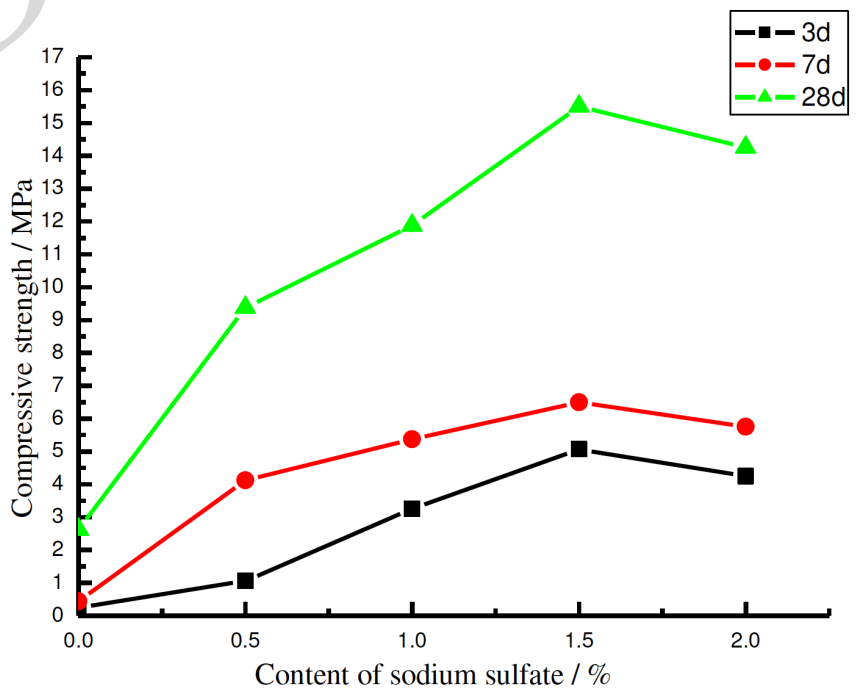

Fig. (3). Influence of $\mathrm{Na}_{2} \mathrm{SO}_{4}$ on compression strength.

It reveals that, $\mathrm{Na}_{2} \mathrm{SO}_{4}$ can take dramatic effect on hydration of steel slag. Vitreous network structure of steel slag can be destructed more thoroughly, more hydration products can be formed in early stage [10]. XRD patterns show that the main products are consist of calcium silicate hydrates, calcium hydroxide and Aft. These hydrate products are bonded together, fill in the voids of paste, the density increase, and lead to higher strength. But when the content of sodium sulfate is more than $2.0 \%$, PH value is changed, 


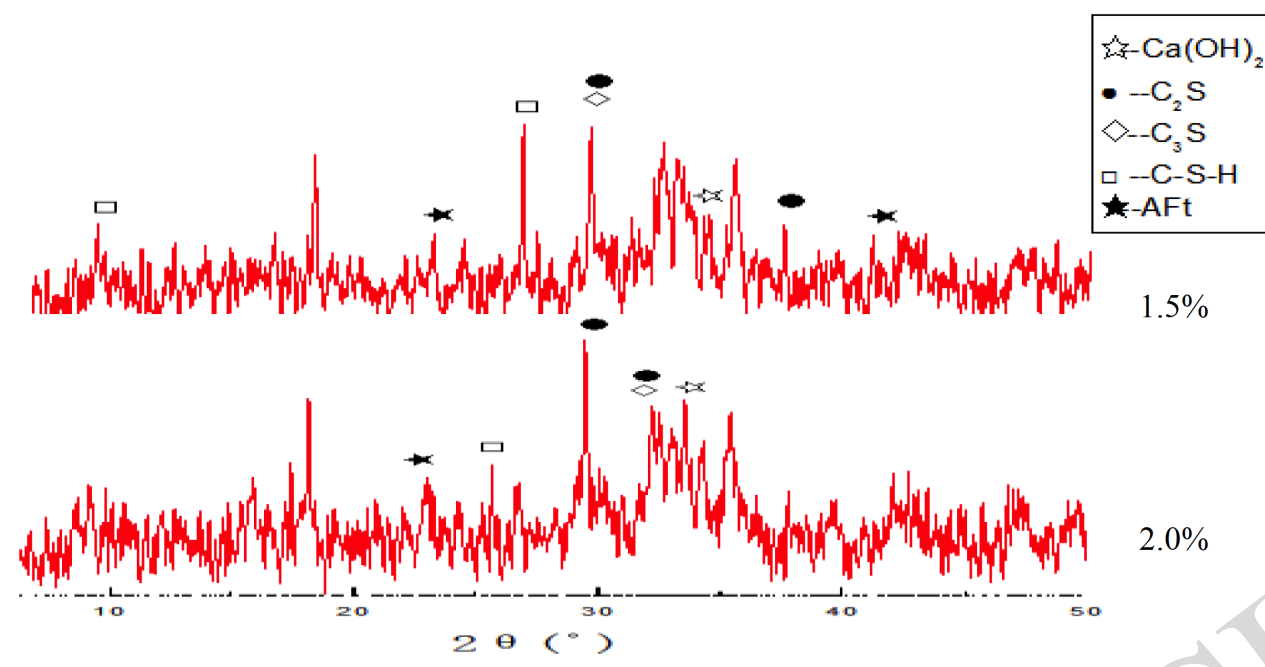

Fig. (4). XRD of samples with $1.5 \%$ and $2.0 \%$ sodium sulfate at $28 \mathrm{~d}$.

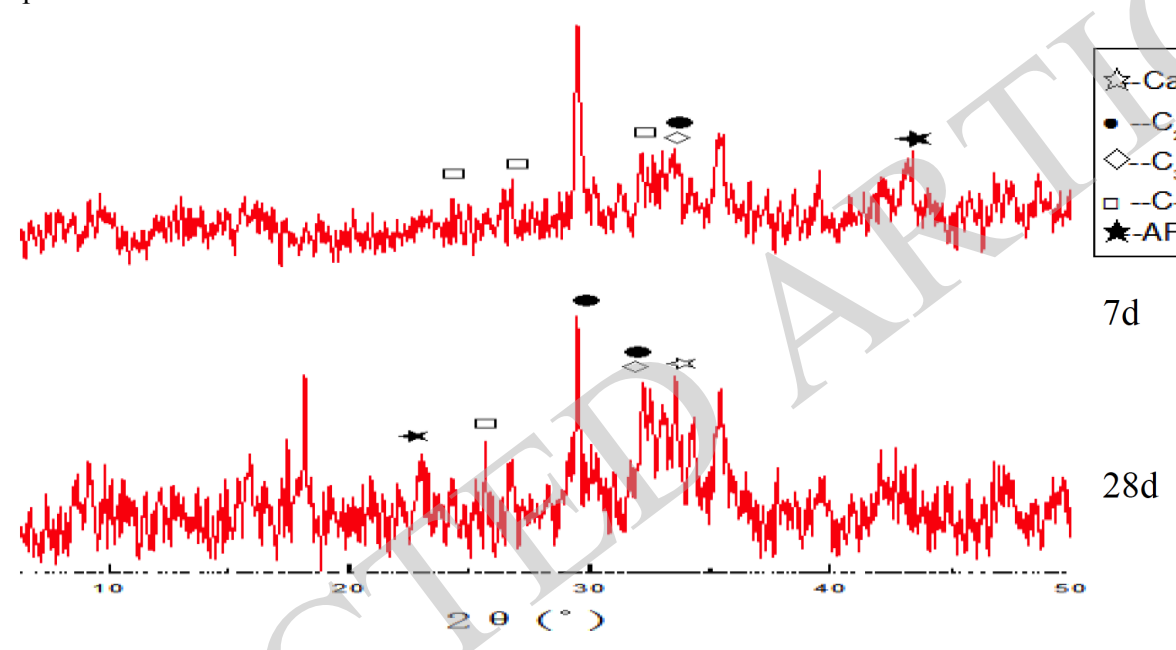

Fig. (5). XRD of samples with $2.0 \%$ sodium sulfate at $7 \mathrm{~d}$ and $28 \mathrm{~d}$.

formation of Aft is affected, which result in poor strength and floating hoarfrost on surface of specimen.

\subsection{XRD Analysis}

XRD patterns of various samples with $1.5 \%$ and $2.0 \%$ sodium sulfate at $28 \mathrm{~d}$ are shown in Fig. (4). It can be seen that, the main products are consist of calcium silicate hydrates, calcium hydroxide and Aft. The amount of hydrates is various with the different content of sodium sulfate. When the content of sodium sulfate is $1.5 \%$, more peaks appeared in XRD patterns, more Aft are formed in paste, higher strength is obtained.

XRD patterns of the hardened specimen with $2.0 \%$ sodium sulfate at $7 \mathrm{~d}$ and $28 \mathrm{~d}$ are shown in Fig. (5). It can be seen that, with time going on, hydration products have a better growth and a higher degree of crystallinity, formation of gels and Aft are improved, the strength of paste can be enhanced.

\section{CONCLUSION}

Different kind of activators can effectively enhance hydration of steel slag to varying degrees. More hydration products can be formed during the hydration process. Mechanical properties both in early and later stage could be enhanced.

When the content of gypsum is $1.5 \%$, the $3 \mathrm{~d}$ strength increases to $1.2 \mathrm{MPa}, 7 \mathrm{~d}$ strength increases to $3.3 \mathrm{MPa}, 28 \mathrm{~d}$ strength increases to $5.0 \mathrm{MPa}$. gypsum can enhance hydration of steel slag in paste. $\mathrm{Ca}^{2+}$ and $\mathrm{SO}_{4}{ }^{2-}$ are provided by gypsum, $\mathrm{SiO}_{2}, \mathrm{Fe}_{2} \mathrm{O}_{3}$ and $\mathrm{Al}_{2} \mathrm{O}_{3}$ in steel slag act with $\mathrm{Ca}(\mathrm{OH})_{2}$, hydrates such as calcium silicate hydrates, are generated in the paste. Enhancement of early strength may be attributed to rapidly consumption of $\mathrm{Al}_{2} \mathrm{O}_{3}$ in steel slag and $\mathrm{Ca}(\mathrm{OH})_{2}$. With time going on, nuclear of liquid phase increase, small size crystals generate and contact each other.

As the content of $\mathrm{Na}_{2} \mathrm{SO}_{4}$ is $1.5 \%$, the $3 \mathrm{~d}$ strength increases to $5.1 \mathrm{MPa}, 7 \mathrm{~d}$ strength increases to $6.5 \mathrm{MPa}, 28 \mathrm{~d}$ strength increases to $15.5 \mathrm{MPa}$. XRD patterns show that the main products are consist of calcium silicate hydrates, calcium hydroxide and Aft. These hydrates are bonded together, fill in the void of paste, the density increase, and lead to higher strength. But when the content of sodium sulfate is more than $2.0 \%$, PH value is changed, formation of Aft is affected, which result in poor strength and floating hoarfrost on surface of specimen. 


\section{CONFLICT OF INTEREST}

The authors confirm that this article content has no conflict of interest.

\section{ACKNOWLEDGEMENTS}

The writers are grateful for support provided through the youth foundation of Hebei Educational Committee (NO. Q2012023).

\section{DISCLOSURE}

"Part of this article has been previously published in Journal of Chemical and Pharmaceutical Research, 2014, 6(10):458-462".

\section{REFERENCES}

Shi C. Steel slag-its production, processing, characteristics, and cementitious properties. J Mat Civil Eng 2004; 16: 230-236.
[2] Li J, Yu Q, Wei J, et al. Structural characteristics and hydration kinetics of modified steel slag. Cement and Concrete Research 2011; 41: 324-9.

[3] Motz H, Geiseler J. Products of steel slags-an opportunity to save natural resources. Waste Manage 2001; 21: 285-93.

[4] Zhu L, Zhao Y. Experiment Study of Steel Slag Compounded Activators. Bull Chin Cer Soci 2010; 29: 1164-8.

[5] Zhu G, Sun S. Effect of composition on activity of steel slag. Chin Steel 2010: 20-4.

[6] Zhang Z, Xu L, Yu G, et al. Influences of the powder of steel slag and granulated blast furnace slag by mechanical activation. Concrete 2010: 92-4.

[7] Kriskova L, Pontikes Y, Cize O. "Effect of mechanical activation on the hydraulic properties of stainless steel slags", Cement and Concrete Res 2012; 42: 778-88.

[8] Wang Q, Yan P. Hydration properties of basic oxygen furnace steel slag. Construct Build Mat 2010; 24: 1134-40.

[9] Wu G, Shang J. Research on Effect of Grinding Aids on the Steel Slag Cementitious Activity. Non-Metallic Mines 2013;36: 30-2.

[10] Tang Z, Wang J, Dong T. Research on Effect of Activator on Early Activity of Steel Slag. Coal Ash 2013: 18-20.

[11] Dong T, Tao Z, Chang Q. Impact of different stimulator on hydration activity of steel slag. Cem Eng 2007; 9: 78-88.

(C) Liu and Chen; Licensee Bentham Open.

This is an open access article licensed under the terms of the Creative Commons Attribution Non-Commercial License (http://creativecommons.org/licenses/ by-nc/3.0/) which permits unrestricted, non-commercial use, distribution and reproduction in any medium, provided the work is properly cited. 